\title{
Ultrastructural characterization of noradrenergic axons and beta-adrenergic receptors in the lateral nucleus of the amygdala
}

\author{
Claudia R. Farb ${ }^{1}{ }^{*}$, William Chang ${ }^{1}$ and J.E. LeDoux ${ }^{1,2}$ \\ Center for Neural Science, New York University, New York, NY, USA \\ 2 The Emotional Brain Institute and the Nathan Kline Institute, Orangeburg, NY, USA
}

\section{Edited by:}

Carmen Sandi, Ecole Polytechnique

Federale De Lausanne, Switzerland

\section{Reviewed by:}

Teresa A. Milner, Weill-Cornell Medical College, USA

Alexander McDonald, University of South Carolina School of Medicine, USA

\section{*Correspondence:}

Claudia R. Farb, Center for Neural

Science, New York University,

4 Washington Place/Room 809,

New York, New York 10003, USA.

e-mail: claudia@cns.nyu.edu
Norepinephrine (NE) is thought to play a key role in fear and anxiety, but its role in amygdaladependent Pavlovian fear conditioning, a major model for understanding the neural basis of fear, is poorly understood. The lateral nucleus of the amygdala $(L A)$ is a critical brain region for fear learning and regulating the effects of stress on memory. To understand better the cellular mechanisms of $\mathrm{NE}$ and its adrenergic receptors in the $L A$, we used antibodies directed against dopamine beta-hydroxylase $(\mathrm{D} \beta \mathrm{H})$, the synthetic enzyme for $\mathrm{NE}$, or against two different isoforms of the beta-adrenergic receptors ( $\beta A R s)$, one that predominately recognizes neurons ( $\beta A R 248$ ) and the other astrocytes ( $\beta A R$ 404), to characterize the microenvironments of $D \beta H$ and $\beta A R$. By electron microscopy, most $\mathrm{D} \beta \mathrm{H}$ terminals did not make synapses, but when they did, they formed both asymmetric and symmetric synapses. By light microscopy, $\beta A R s$ were present in both neurons and astrocytes. Confocal microscopy revealed that both excitatory and inhibitory neurons express $\beta A R 248$. By electron microscopy, $\beta A R 248$ was present in neuronal cell bodies, dendritic shafts and spines, and some axon terminals and astrocytes. When in dendrites and spines, $\beta A R 248$ was frequently concentrated along plasma membranes and at post-synaptic densities of asymmetric (excitatory) synapses. $\beta A R 404$ was expressed predominately in astrocytic cell bodies and processes. These astrocytic processes were frequently interposed between unlabeled terminals or ensheathed asymmetric synapses. Our findings provide a morphological basis for understanding ways in which NE may modulate transmission by acting via synaptic or non-synaptic mechanisms in the LA.

Keywords: norepinephrine, DBH, synapse, volume transmission, astrocyte, electron microscopy, fear, lateral amygdala

\section{INTRODUCTION}

Norepinephrine (NE) has long been implicated in fear and anxiety (Gray, 1978; Redmond, 1979; Aston-Jones and Bloom, 1981; Aston-Jones et al., 1999, 2000; Sullivan et al., 1999), and is known to play a role in learning and memory (Ferry et al., 1997; Bailey et al., 2000; McGaugh, 2002). However, the contribution of NE to Pavlovian fear conditioning, a leading model for understanding the neural basis of fear and anxiety and learning and memory, is poorly understood. Recent studies suggest that NE contributes to the acquisition but not the consolidation of fear conditioning (Lee et al., 2001; Debiec and LeDoux, 2004; Grillon et al., 2004; Murchison et al., 2004; Bush et al., 2010). The lateral nucleus of the amygdala (LA) is a critical brain region for fear learning (LeDoux, 2000, 2007; Rodrigues et al., 2004; Maren, 2005; Lang and Davis, 2006 ) and blocking beta-adrenergic receptors ( $\beta A R s$ ) within the LA disrupts the acquisition of fear conditioning (Bush et al., 2010). Previous studies have shown that the amygdala is extensively innervated by noradrenergic fibers, primarily originating from the locus coerulus (Moore and Card, 1984; Fallon and Ciofi, 1992; Asan, 1993, 1998). Several studies have examined the ultrastructural relations of NE terminals in the basolateral complex or basolateral nucleus (BLA) (Asan, 1993, 1998; Li et al., 2001, 2002). However, the BLA contains two major subdivisions, the LA and the basal nucleus
(B), each with distinct connections (Pitkänen et al., 1997), and the LA, but not the B, is necessary for fear conditioning (Amorapanth et al., 2000; Nader et al., 2001). Moreover, the results of these ultrastructural NE studies differed: one study showed that within the basal complex, NE terminals rarely formed synapses (Asan, 1998) while another showed a greater proportion of NE terminals forming synapses, including with other terminals (Li et al., 2001). Electrophysiological studies have shown that $\beta$ ARs play a role in synaptic transmission (Gean et al., 1992; Huang et al., 1993, 1996; Ferry et al., 1997; Buffalari and Grace, 2007) and LTP (Johnson et al., 2006) in the amygdala. While anatomical studies have characterized the cellular and subcellular distribution of $\beta$ ARs in other brain regions (Aoki et al., 1989; Aoki, 1992, 1997; Aoki and Pickel, 1992; Milner et al., 2000), little is known about the cellular and subcellular distribution of $\beta$ ARs within the amygdala. Using commercial antibodies directed against the $\beta_{1}$ and $\beta_{2}$ receptor subtypes, one confocal microscopic study found that the $\beta_{1}$ and $\beta_{2}$ receptor subtypes are widely distributed in basal amygdala neurons but not in astrocytes (Qu et al., 2008). This group also found that while both receptor subtypes were seen in the membranes and cytoplasm of cell bodies, the $\beta_{2}$ receptor subtype, but not the $\beta_{1}$, was localized to the nucleus. To understand better the cellular mechanisms of NE's contributions to fear learning, we examined the anatomical 
organization of NE terminals and $\beta$ ARs in the LA. In this study, we employed immunoelectron microscopy to determine whether terminals immunoreactive for dopamine beta-hydroxylase $(\mathrm{D} \beta \mathrm{H})$, the synthetic enzyme for NE, form synaptic junctions in the LA and if so, examine these synapses and identify the post-synaptic targets on NE terminals. To determine the cellular and subcellular distributions of $\beta A R$ in the LA, we used previously characterized antibodies directed against two different isoforms of $\beta$ ARs: $\beta A R 248$, an antibody that predominately recognizes neurons, and BAR404, which primarily detects astrocytes.

\section{MATERIALS AND METHODS}

Male Sprague-Dawley (Hilltop Lab Animals, Inc; Scottdale, PA, USA) rats weighing 300-400 g $(n=8)$ were used for studies. All procedures used were approved by the Animal Use and Care Committee of New York University, and conform to the guidelines of the National Institutes of Health on Care and Use of Experimental Animals in Research.

\section{TISSUE FIXATION}

Naïve animals were anaesthetized with chloral hydrate $(25 \%$; $1-1.5 \mathrm{~g} / \mathrm{kg} \mathrm{BW}$ ) and transcardially perfused with $25-30 \mathrm{ml}$ of heparinized $0.9 \%$ saline followed by either: $50 \mathrm{ml}$ of $3.0 \%$ acrolein mixed into $4 \%$ paraformaldehyde (PFA), followed by $450 \mathrm{ml}$ of $4 \%$ PFA dissolved in $0.1 \mathrm{M}$ phosphate buffer $(\mathrm{PB}, \mathrm{pH} 7.4 ; n=4)$, or $500 \mathrm{ml} 0.1 \%$ glutaraldehyde/4\% PFA $(n=4)$. The brains were removed from the skull, blocked, and post-fixed in 4\% PFA for $30 \mathrm{~min}$. Blocks containing the amygdala were cut on a Vibratome and $40-\mu \mathrm{m}$ coronal sections were collected. Tissue sections were treated with $1 \%$ sodium borohydride in $\mathrm{PB}$ for $30 \mathrm{~min}$ and rinsed with phosphate-buffered saline (0.01 M PBS, pH. 7.4).

\section{IMMUNOCYTOCHEMICAL LABELING}

Following rinses in PBS, tissue sections were preincubated in PBS containing 1\% (w:v) bovine serum albumin (BSA) for $30 \mathrm{~min}$. The sections were incubated overnight at room temperature with either a mouse monoclonal antibody directed against $\mathrm{D} \beta \mathrm{H}(1: 500$; Millipore, Temecula, CA, USA) or rabbit polyclonal antiserum directed against the one of the $\beta$-adrenergic receptors. The following day, the tissue was rinsed in PBS, incubated for $30 \mathrm{~min}$ in a solution containing a 1:200 dilution of either goat anti-mouse for $\mathrm{D} \beta \mathrm{H}$ or goat anti-rabbit biotinylated IgG for $\beta \mathrm{AR}$ (1:200; Vector Labs, Burlingame, CA, USA), rinsed, and incubated for $30 \mathrm{~min}$ in $\mathrm{ABC}$ (Vector Labs) solution. The reaction product was then visualized by incubation in $0.022 \% 3$-3'-diaminobenzidine (DAB; Sigma, St. Louis, MO, USA) and $0.003 \%$ hydrogen peroxide. All primary and secondary antisera incubations included 1\% BSA and diluents containing PBS. Triton-X was added to the $\mathrm{D} \beta \mathrm{H}$ primary antibody solution ( $0.2 \%$ for light microscopy, $0.05 \%$ for electron microscopy). All incubations were performed at room temperature with continuous agitation. For dual-label fluorescent experiments, tissue was incubated overnight in $\beta A R 248$ as described above, rinsed, and incubated with goat anti-rabbit IgG conjugated to Alexa 594 (1:200; Invitrogen, Carlsbad, CA, USA) for $1 \mathrm{~h}$. The tissue was then rinsed, preincubated in 1\% BSA and incubated overnight in either antibodies made in mouse either to GABA (1:2000; ICN Biochemicals, Costa Mesa, CA, USA) or CAMKII (1:200; Upstate,
Lake Placid, NY, USA). The following day, the tissue was rinsed, and incubated in goat anti-mouse conjugated to Alexa 488 (1:200). Tissue sections for light and confocal microscopy were mounted on slides coated with gelatin. Tissue sections designated for LM analysis were dehydrated in a graded series of alcohol, defatted in xylene and coverslippped with Permount (Fisher Scientific). Fluorescent tissue was mounted and coverslipped with Prolong Gold (Invitrogen). The final preparations were examined on either a Nikon FXA and photographed with a Coolsnap digital camera (Roper Scientific, Trenton, NJ, USA) or a Zeiss LSM 310 and Leica TCS SP2 confocal microscope.

\section{ELECTRON MICROSCOPIC PROCESSING}

Tissue sections designated for EM were processed as previously described (Farb and LeDoux, 1997).In brief, tissue sections containing the amygdala were incubated in $1 \%$ osmium tetraoxide/PB, dehydrated in a graded series of alcohols, stained en bloc in uranyl acetate, further dehydrated in acetone and subsequently flat-embedded in EMbed. Portions of the tissue containing the amygdala were cut and glued (Super Glue; Rancho Cucamonga, CA, USA) onto Beem capsules and placed at $60^{\circ} \mathrm{C}$ for $10 \mathrm{~min}$. Photographs of the amygdala were taken and ultrathin sections $(85 \mathrm{~nm})$ were cut from the dorsolateral division of the LA (Figure 1A). Ultrathin sections were collected on 8-12 nickel grids and the tissue was examined on a JEOL 1200EX electron microscope. Photographs were taken using a Hammamatsu digital camera (AMT; Danvers, MA, USA). Electron micrographs were collected from the dorsolateral amygdala of four animals with the best morphological preservation. For each brain, ultrathin sections from at least two vibratome sections containing the AL were examined. Labeled terminals were identified by the presence of peroxidase reaction product within processes and were distinguished from preterminal axons by the presence of vesicles. Immunoreactive terminals without distinct membrane boundaries or whose peroxidase reaction product was too dense to distinguish between it and the post-synaptic density were not included in the analysis. Immunoreactive terminals were characterized as either forming or not forming synaptic contacts by the presence of a post-synaptic membrane specialization, intercleft filaments, and widened (10-20 nm) parallel spacing of plasma membranes (Peters et al., 1991). Labeled terminals with thickened post-synaptic densities and widened synaptic clefts were classified as asymmetric while terminals with thin post-synaptic densities and narrower synaptic clefts were identified as symmetric. Appositions were characterized by close membrane associations not separated by astrocytic processes, the lack of conventional synaptic clefts, intercleft material or dense specializations. Dendritic shafts were arbitrarily characterized as large (i.e. proximal) if their diameter was greater than $0.5 \mu \mathrm{m}$, or small (i.e., distal) if their diameter was less than $0.5 \mu \mathrm{m}$. Dendritic spines were smaller than dendrites and lacked mitochondria.

\section{ANTIBODY SPECIFICITY}

In this study, we used mouse monoclonal antibodies directed against $\mathrm{D} \beta \mathrm{H}, \mathrm{CAMKII}$, and GABA that have been characterized in previously published reports ( $\mathrm{Li}$ et al., 2002; McDonald et al., 2002; Balcita-Pedicino and Rinaman, 2007; Schiltz and Sawchenko, 2007; Howorth et al., 2009). The pattern of D $\beta \mathrm{H}$-immunoreactivity we describe is consistent with previously published reports in the amygdala complex (Fallon et al., 1978; Fallon and Ciofi, 1992; 
Roder and Ciriello, 1993; Asan, 1993, 1998; Li et al., 2001,2002).Earlier studies have shown that within the LA, D $\beta \mathrm{H}$ is a specific marker for $\mathrm{NE}$ and does not label the other catecholaminergic biosynthetic enzymes, phenyl-methyl transferase (PNMT), the marker for adrenergic axons, or tyrosine-hydroxylase ( $\mathrm{TH}$ ), the marker for dopaminergic axons (Fallon et al., 1978; Fallon and Ciofi, 1992; Asan, 1993; Roder and Ciriello, 1993). Specifically, these studies have shown that PNMT immunoreactivity in the LA is scarce or nearly absent while TH-ir differs markedly and is non-overlapping. We also used rabbit antisera directed against $\beta_{2} \mathrm{AR}$ that was generated by using synthetic peptides corresponding to amino acids 248-256 ( $\beta$ AR 248) and 404418 ( $\beta$ AR 404) of hamster lung $\beta_{2}$ ARs (Dixon et al., 1986). The $\beta A R$ 404 antiserum recognizes both the $\beta_{1}$ - and $\beta_{2}$-subtypes (Strader et al., $1987 \mathrm{a}, \mathrm{b})$. The antiserum to $\beta$ AR $248(1: 1 \mathrm{~K})$ was directed against the third cytoplasmic loop while the antiserum for $\beta A R 404$ (1:1K) was directed against the C-terminus of the receptor. The specificity of BAR 404 antisera has been previously characterized using Western blot (Strader et al., 1987b) and immunoprecipitation of radiolabeled BAR (Strader et al., 1987a). Preadsorption controls to the synthetic peptides using the exact correspondence to the antigens that were used to generate the $\beta$ AR 248 and 404 antisera were also performed (Aoki, 1997). Antisera against $\beta A R 248$ and $\beta A R 404$ were generously provided by Dr. C.D Strader of Merck Sharp and Dohme Research Laboratories. Immunoreactivity was absent from tissue in which the primary antisera was omitted from the incubation solutions or the secondary antibody was mismatched to the primary antibody, e.g., anti-mouse IgG instead of the anti-rabbit IgG, and the tissue was reacted as described above.

\section{RESULTS \\ LIGHT MICROSCOPY}

The LA contains a dense plexus of dopamine beta-hydroxylase fibers

The pattern of $\mathrm{D} \beta \mathrm{H}$-immunoreactivity (-ir) in the amygdala has been described previously (Moore and Card, 1984; Fallon and Ciofi, 1992; Asan, 1993, 1998; Li et al., 2001, 2002). In brief, in both glutaraldehyde and acrolein-fixed tissue, $\mathrm{D} \beta \mathrm{H}$ fibers appeared as a dense plexus and were distributed throughout the LA (Figure 1A). D $\beta H$ fibers were fine and varicose and coursed through the amygdala in both dorsal-ventral and medial-lateral directions (Figure 1B).

\section{Beta-adrenergic receptor immunoreactivity occurs throughout the $L A$} Immunoreactivity for both $\beta_{2} A R$ antisera was distributed throughout the LA. By light microscopy, numerous cells were labeled. (Figures 1C,D). $\beta A R 248$ densely labeled neuronal perikarya and the proximal portions of their dendrites. In some LA cells, the reaction product rimmed the cytoplasm and the nucleus was well delineated whereas in other cells, the reaction product obscured the nuclei (Figure 1E). $\beta A R$ 404-ir was observed in small cell bodies that appeared astrocytic: many labeled processes radiated from small perikarya (Figure 1F). Some labeled processes followed the contours of blood vessels.

\section{CONFOCAL MICROSCOPY REVEALS $\beta$ ARS ARE LOCALIZED TO BOTH EXCITATORY AND INHIBITORY CELLS}

To determine whether $\beta$ AR248 was localized to specific cells types, we dually labeled tissue for $\beta A R 248$ and CAMKII, a marker for excitatory, pyramidal-like cells in the LA (McDonald et al., 2002) and

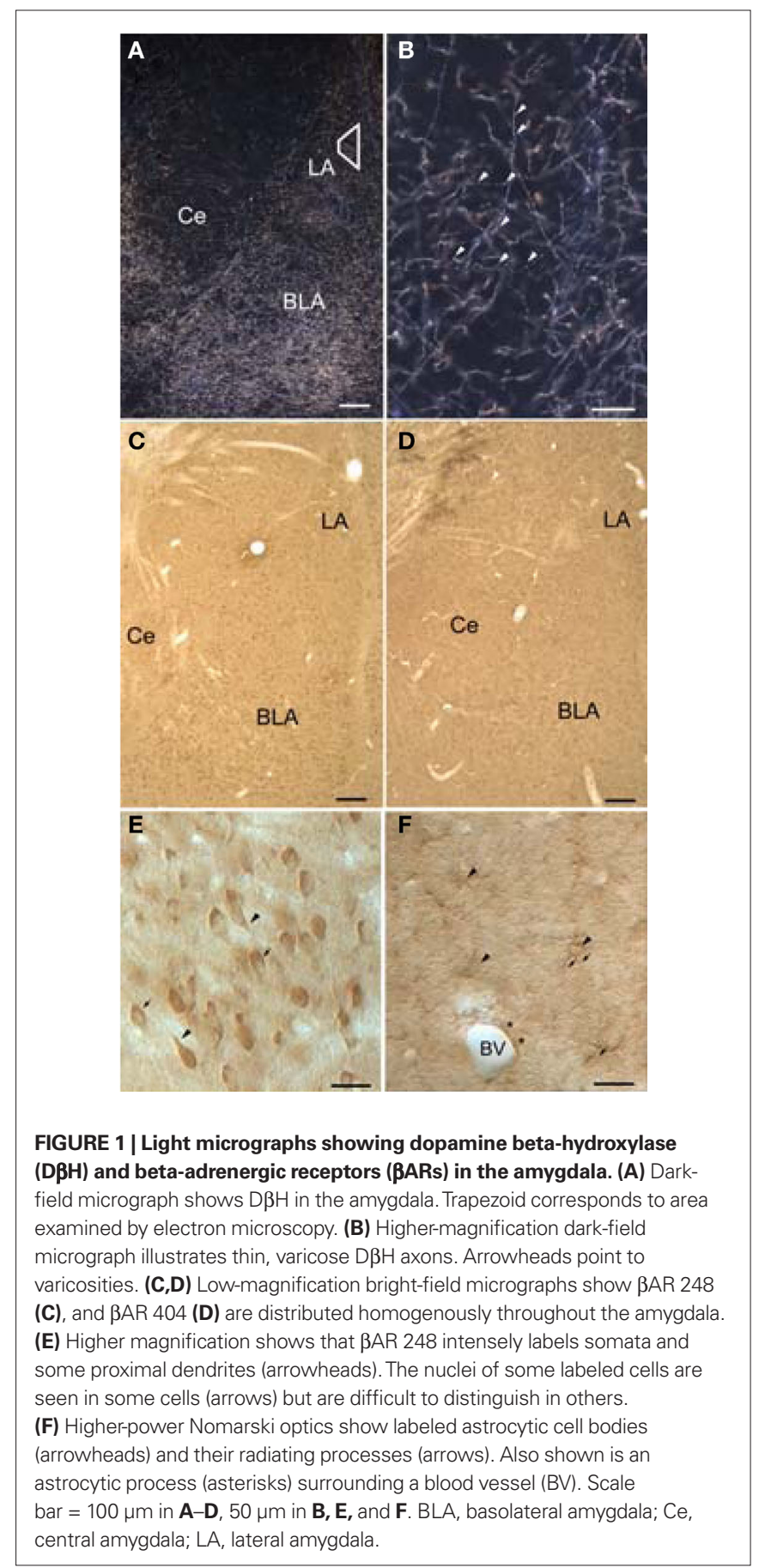

examined the tissue by confocal microscopy. We also dually labeled tissue for $\beta A R 248$ and GABA to establish whether GABAergic cells contain $\beta$ ARs. By confocal microscopy, $\beta$ ARs were localized to both LA excitatory and inhibitory cells (Figures 2A,B).

\section{ELECTRON MICROSCOPY}

\section{Most D $\beta$ H terminals do not form synapses within single sections}

Most of our EM analysis was performed on tissue fixed with acrolein since both the ultrastructure and membrane preservation were superior to tissue fixed with low levels of glutaraldehyde. Four hun- 


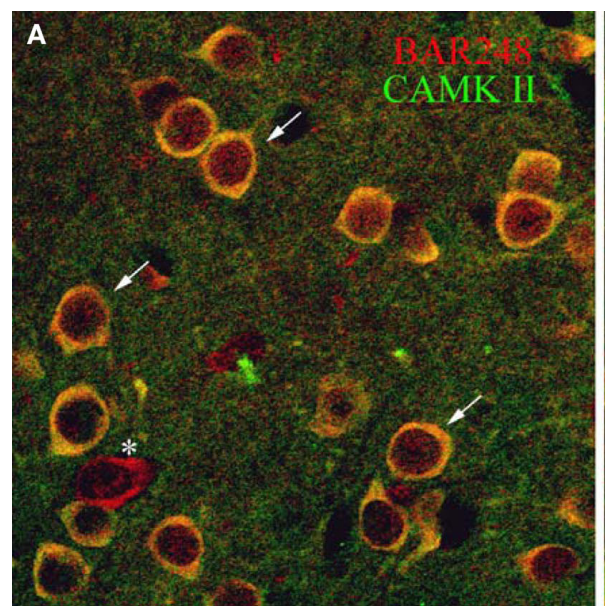

FIGURE 2 | Confocal micrographs show that $\beta A R 248$ is localized to both excitatory and inhibitory LA cells. (A) Cells immunopositive for CAMKII (green) are also immunoreactive for $\beta A R 248$ (red). Arrows point to dually labeled cells

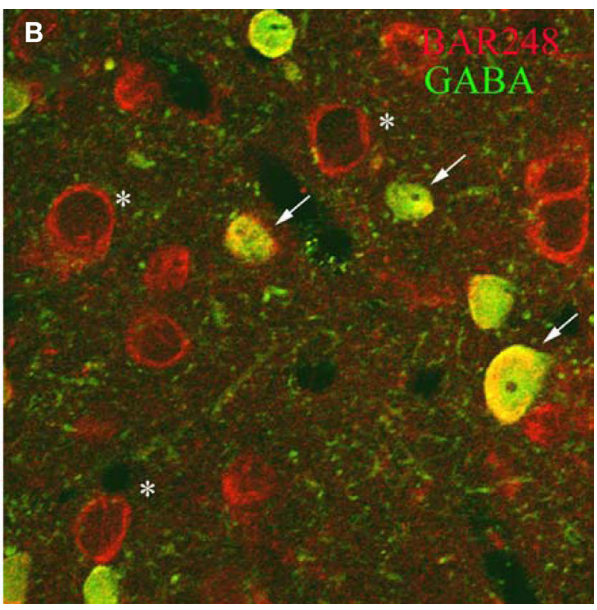

while the asterisk indicates a cell singly labeled for $\beta A R$ 248. (B) GABAergic cells (green) also contain $\beta A R 248$ (red). Arrows point to cells dually labeled for $\beta A R$ 248 and GABA; asterisks indicate $\beta A R 248$ singly labeled cells. dred and ten $\mathrm{D} \beta \mathrm{H}$-labeled terminals were analyzed from tissue taken from the four animals with the best morphology. Analysis was performed on three animals perfused with acrolein and one animal perfused with glutaraldehyde. Ultrathin sections were collected from 3-4 vibratome sections from each animal for a total of 14 samples. D $\beta \mathrm{H}$-labeled terminals were unmyelinated and varied in size from $0.4-1.5 \mu \mathrm{m}$. D $\beta \mathrm{H}$ terminals contained small, clear vesicles, though many terminals also contained 1-5 densecore vesicles (Figures 3A-F). D $\beta \mathrm{H}$ terminals frequently contained mitochondria and some $\mathrm{D} \beta \mathrm{H}$-labeled axons appeared to follow the contours of blood vessels (Figure 4A). Frequently, the reaction product filled the axoplasm and obscured the morphological features of the terminal. Those terminals whose membranes were not intact due to the use of detergent were not included in the analysis. The vast majority of $\mathrm{D} \beta \mathrm{H}$ terminals did not form synapses in a single plane of section (282/410 or 69\%) (Figures 3A,E). About half the $\mathrm{D} \beta \mathrm{H}$ terminals $(223 / 410$, or $54 \%$ ) were directly apposed to unlabeled terminals (Figures 3B,C,E,F). In some instances (9/410 or $2 \%$ ) possible axo-axonic contacts were observed: the plasma membranes of $\mathrm{D} \beta \mathrm{H}$ terminals showed close and parallel alignment with the plasma membrane of unlabeled terminals and some intercleft density was present (Figure 4A). When D $3 \mathrm{H}$ terminals did form synapses, most formed symmetric synapses (90/128 or $70 \%$ ) (Figure 5A) and the vast majority of these (75/90, 83\%) occurred on dendrites (Figures 3B,D) though some symmetric synapses were made on spines $(13 / 90,14 \%)$ and two occurred on somata $(2 / 90,2 \%)$. D $\beta H$ symmetric synapses on spines usually occurred on the spine neck. When $\mathrm{D} \beta \mathrm{H}$ terminals formed junctions on spines, almost one-quarter (9/37 or 24\%) of these spines received another synapse from an unlabeled terminal. Most of these second synapses were asymmetric ( $8 / 9$ or $89 \%)$ and were formed on the spine head. Almost one-third of synapse-forming $\mathrm{D} \beta \mathrm{H}$ terminals made asymmetric synapses (38/128 or 30\%). The majority of asymmetric synapses occurred on spines (24/38, or 63\%) (Figures $3 F$ and $5 B$ ), though many were formed on dendrites (14/38 or 37\%) (Figures 3C and 5B).

\section{BAR IMMUNOREACTIVITY}

$\beta A R 248$ is frequently localized to post-synaptic densities. By electron microscopy, $\beta$ AR 248-ir was localized to neuronal perikarya, large and small dendritic shafts, dendritic spines, some axon terminals, and astrocytic processes (Figures 6A-C). Within dendritic shafts, reaction product rimmed the microtubules and the mitochondrial membranes, and in both shafts and spines was frequently concentrated along the plasma membranes and at post-synaptic densities (Figures 6A-C). $\beta A R$ 248-ir axon terminals forming asymmetric synapses were occasionally observed (Figure 6B). $\beta A R$ 248 -ir was seen in perikarya with the morphological features of both inhibitory, e.g., invaginated nuclei and abundant cytoplasm, and excitatory cells, e.g., large nuclei and a thin rim of cytoplasm (Ribak and Seress, 1983; Farb et al., 1995). The subcellular distribution of $\beta$ AR 248 immunoreactivity was consistent with previously published studies (Aoki, 1992, 1997).

$\beta A R \quad 404$ is predominantly localized to glial processes. Ultrastructural examination revealed that $\beta$ AR 404 was predominantly localized to glial perikarya and processes but some neuronal processes were also immunoreactive (Figures 6D-F). Glial perikarya were distinguished from neuronal perikarya by the presence of filamentous organelles or glycogen granules whereas glial processes were recognized by their irregular contours and scarcity of organelles. When $\beta$ AR 404 immunoreactivity occurred in large glial processes, the immunoperoxidase product rimmed the glial vesicles and mitochondria but was frequently concentrated along the plasma membranes (Figure 6E). Labeled glial processes frequently ensheathed or directly apposed unlabeled terminals forming asymmetric terminals (Figures 6D-F). Often, small labeled glial processes were interposed between unlabeled axon terminals (Figure 6D). Some axon terminals and dendritic shafts and spines were also immunoreactive for $\beta A R 404$ (Figures 6D,F). Large glial processes intensely immunoreactive for $\beta A R 404$ were sometimes apposed to the basal lamina and endothelial cells that bounded blood vessels (Figure 4B). 


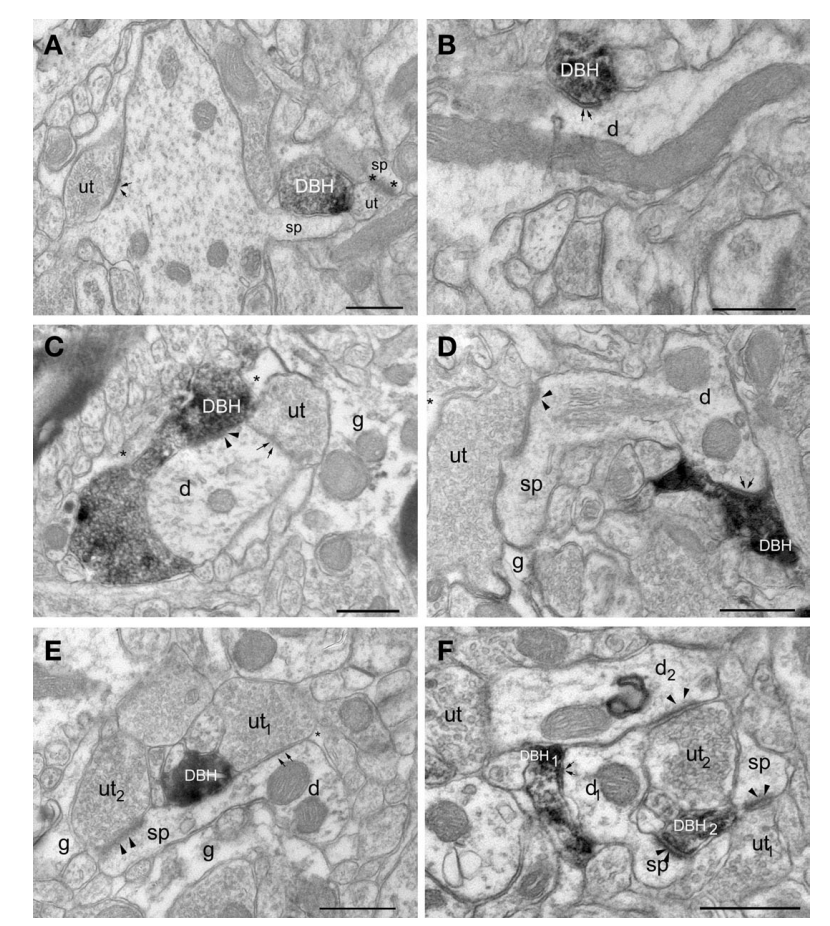

FIGURE 3 | Electron micrographs show D $\beta$ H-terminals in LA. (A) A $\mathrm{D} \beta \mathrm{H}$ - terminal (DBH) apposes a dendritic spine (sp) and an unlabeled terminal (ut) forming an asymmetric synapse (asterisks) onto a spine (sp). (B) A $D \beta H$-terminal forms a symmetric synapse (arrows) with a dendrite (d). (C) A $\mathrm{D} \beta \mathrm{H}$-terminal forms a synapse (arrowheads) onto a dendrite (d) that also receives a synapse (arrows) from an unlabeled terminal (ut). Glial processes (g and asterisk) are also shown. (D) A DBH-terminal forms a symmetric synapse (arrows) onto a dendritic (d) whose spine (sp) receives a synapse (arrowheads) from an unlabeled terminal (ut). Also shown is a glial process (g). (E) A $D \beta H$-terminal is apposed to an unlabeled terminal (ut $)_{1}$ that forms a symmetric synapse (arrows) on a dendrite (d). An unlabeled terminal (ut) forms an asymmetric synapse (arrowheads) on the dendrite's spine (sp). Unlabeled glial processes ( $\mathrm{g}$ and *) are also shown. (F) A D $\beta$ H-terminal $\left(\mathrm{DBH}_{1}\right)$ forms a synapse (arrows) onto a dendritic shaft $\left(\mathrm{d}_{1}\right)$, whose spine $(\mathrm{sp})$ receives an asymmetric synapse (arrowheads) from a second $\mathrm{D} \beta \mathrm{H}$-terminal $\left(\mathrm{DBH}_{2}\right)$. $\mathrm{D} \beta \mathrm{H}_{2}$ apposes unlabeled terminals ( $\mathrm{ut}_{1-2}$ ) forming asymmetric synapses

(arrowheads) with a spine $(\mathrm{sp})$ and a dendrite $\left(\mathrm{d}_{2}\right)$. Scale bars $=0.500 \mu \mathrm{m}$.

\section{DISCUSSION}

The present study used immunocytochemistry to identify and characterize: (1) terminals that contain norepinephrine, and (2) the cellular and subcellular distribution of $\beta$ ARs in the LA. The results show that most $\mathrm{D} \beta \mathrm{H}$ terminals within the LA do not form synaptic junctions, but when they do, most synapses occur on dendritic shafts and a small proportion are formed on dendritic spines. While the majority of $D \beta H$ synapses are symmetric, asymmetric synapses are also formed and most of these occur on spines. $\beta$ ARs are localized to both neurons and glial cells in the LA, and within neurons, $\beta$ ARs are localized to both excitatory and inhibitory cells and are frequently concentrated at the PSDs of dendritic shafts and spines. These results provide the morphological basis for understanding the role that NE and $\beta$ ARs play in modulating synaptic transmission within the LA.

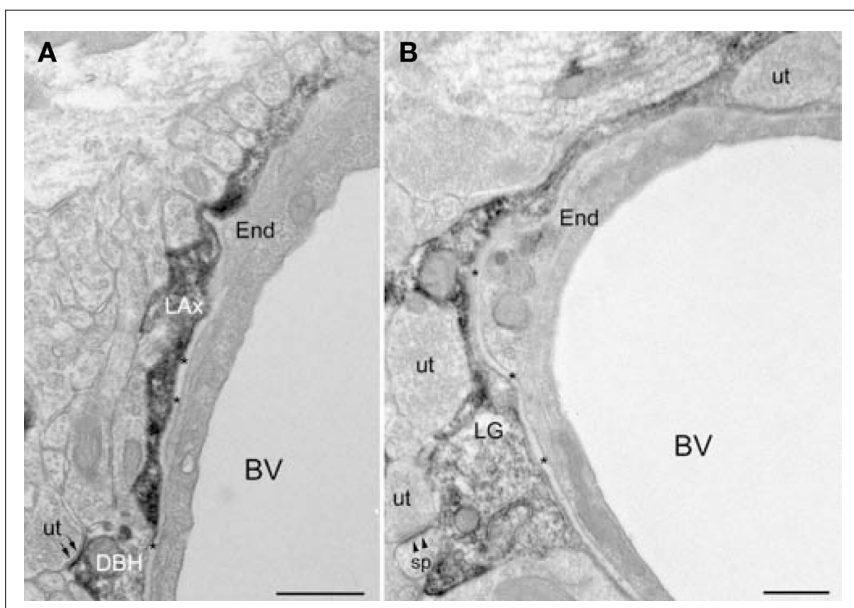

FIGURE 4 | D $\beta H$-profiles and glial processes immunoreactive for $\beta A R 404$ are associated with blood vessels. (A) A D BH-axon (LAX) follows the contours of a blood vessel. The plasma membrane of the $D \beta H$-terminal (DBH) shows parallel alignment with the plasma membrane (small arrows) of an unlabeled terminal (ut). The basal lamina (asterisks) and an endothelial cell (End) separate the D $B$ H-terminal from the blood vessel (BV). (B) A $\beta A R$ 404-labeled glial process (LG) encircles a blood vessel (BV), which is bounded by an endothelial cell (end) and the basal lamina (asterisks). The BAR 404 astrocyte apposes unlabeled terminals (ut), one of which forms an asymmetric synapse (arrowheads) onto a dendritic spine (sp). Scale bars $=0.500 \mu \mathrm{m}$.
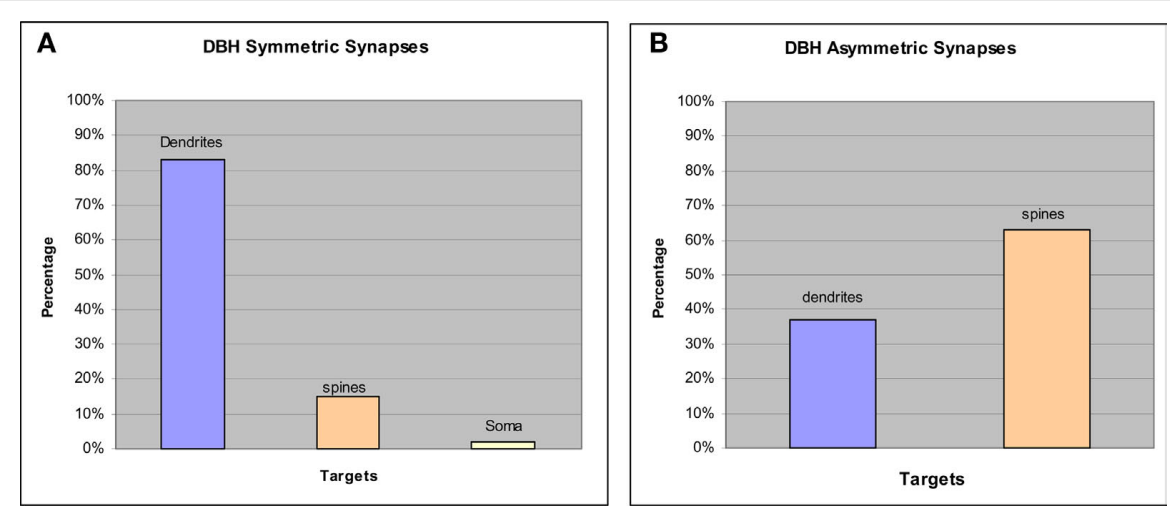

FIGURE 5 | Graphs show synaptic targets and specializations made by D $\beta$ H terminals that form synapses. (A) The vast majority of DBH symmetric synapses occurred on dendrites but a small proportion were made onto spines and somata. (B) Most DBH asymmetric synapses occurred on spines though some were formed on dendrites. 


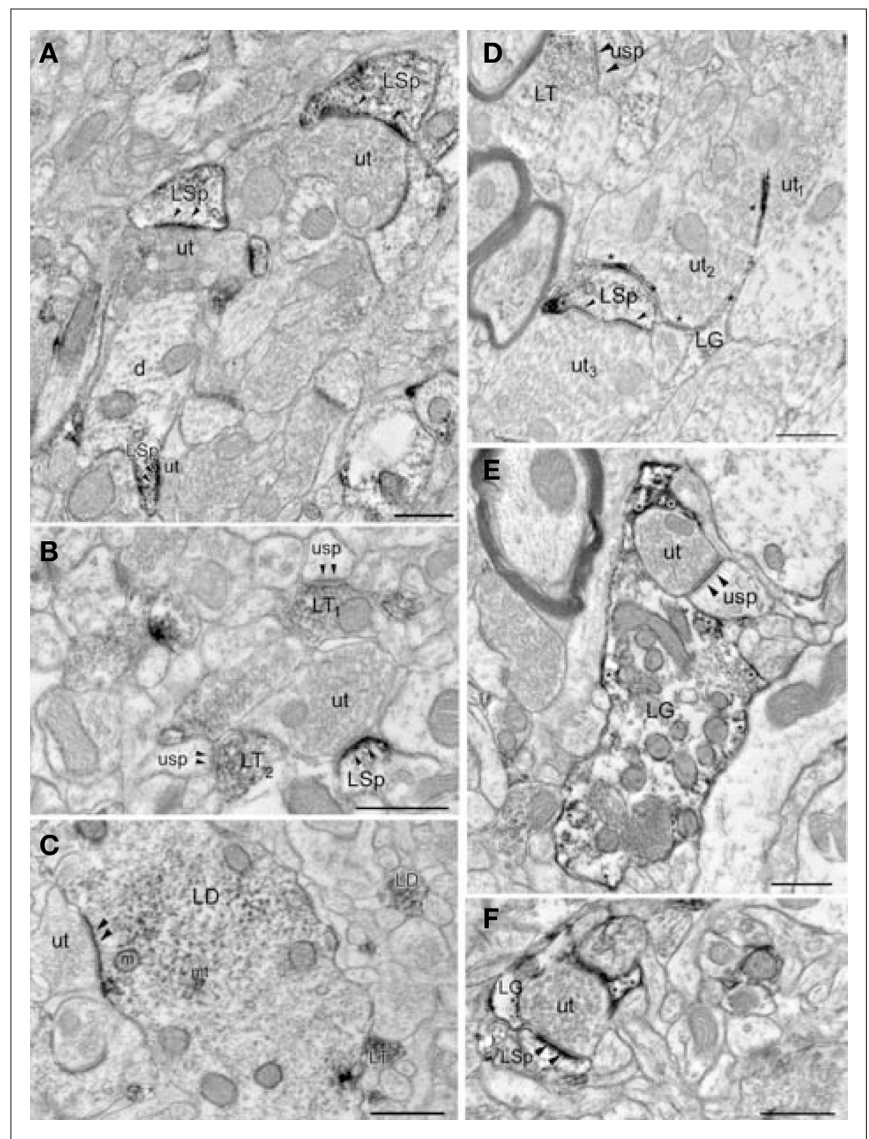

FIGURE 6 | Both LA neurons and glia are immunoreactive (ir) for $\beta$ AR. (A) Unlabeled terminals (ut) form asymmetric synapses onto $\beta A R$ 248-ir spines (LSp). The spinous portion (LSp) of a dendrite (d) is $\beta A R$ 248-ir. (B) An unlabeled terminal (ut) synapses (arrowheads) onto a $\beta A R$ 248-ir spine (LSp). $\beta A R$ 248-labeled terminals ( $L T_{1-2}$ ) synapse (arrowheads) onto unlabeled spines (usp). (C) The $\beta A R 248$ reaction product in a dendrite (LD) is concentrated at the synapse (arrowheads) formed by an unlabeled terminal (ut) but also rims the microtubules $(\mathrm{mt})$ and mitochondria $(\mathrm{m})$. Also shown are a $\beta A R$ 248-ir terminal (LT) and a small labeled dendrite (LD). (D) $\beta A R$ 404-ir glial processes (LG, asterisks) are interposed between two unlabeled terminals ( $\mathrm{ut}_{1-2}$ ). Also shown are an unlabeled terminal (ut ${ }_{3}$ ) synapsing (arrowheads) onto a $\beta A R 404$ ir spine (LSp) and a $\beta A R$ 404-ir terminal (LT) synapsing (arrowheads) onto an unlabeled spine (usp). (E) A $\beta A R$ 404-ir glial process (LG) surrounds a terminal (ut) that synapses (arrowheads) onto a spine (usp). Asterisks denote $\beta A R$ 404-ir along the plasma membrane. (F) A $\beta A R 404$ ir glial process (LG, asterisks) surrounds an unlabeled terminal (ut) that forms an asymmetric synapse (arrowheads) onto a $\beta A R$ 404-ir spine (LSp). Scale bars $=0.500 \mu \mathrm{m}$.

\section{METHODOLOGICAL CONSIDERATIONS OF $\beta$ AR ANTISERA}

The $\beta A R 404$ antibody we used in this study was generated by using synthetic peptides directed against the amino acid sequences of hamster lung $\beta_{2}$ ARs (Dixon et al., 1986) but recognizes both the $\beta_{1}$ - and $\beta_{2}$-subtypes (Strader et al., 1987a,b). This antibody has been extensively characterized using Western blot (Strader et al., 1987b), immunoprecipitation of radiolabeled $\beta$ AR (Strader et al., 1987a) and preadsorption to the synthetic peptides using the exact correspondence to the antigens that were used to generate the antisera (Aoki, 1997). Immunolabeling with the antibody directed against the third intracellular loop, $\beta$ AR 248, was consistent with previous studies, in which a monoclonal antibody directed the third intracellular loop was used (Aoki et al., 1989; Aoki, 1997). Though the results from several autoradiographic (Palacios and Kuhar, 1980; Minneman et al., 1982; Rainbow et al., 1984; Johnson et al., 1989) and in situ (Asanuma et al., 1991; Abraham et al., 2008) studies report different levels of $\beta_{1}$ - and $\beta_{2}$-ARs across various brain regions, each of these studies demonstrated the presence of either $\beta_{1}$ - or $\beta_{2}$-ARs in the amygdala complex and adjacent areas. Though the pattern of $\beta \mathrm{AR}$ immunolabeling we observe is homogenous compared to the distinct patterns reported in the autoradiographic and in situ studies, the antibodies we used likely recognize receptors in the perikaryal cytoplasm undergoing sequestration, desensitization, degradation or synthesis, as well as those that are ligand-binding (Strader et al., 1987a,b; Zemcik and Strader, 1988). Additionally, the antibodies we used recognize both the $\beta_{1}$ - and the $\beta_{2}$-subunits, though they were directed against the $\beta_{2}$ subunit, and recognize a greater population of cells, compared to those identified by in situ. It is thus not unexpected that the distribution of $\beta$ ARs identified by immunolabeling differs from patterns seen by other methods.

\section{SYNAPTIC CHARACTERIZATION OF D $B H$ WITHIN THE LA}

Our results show that most $\mathrm{D} \beta \mathrm{H}$ terminals within single planes of section do not form synapses but instead form non-junctional appositions with dendrites or unlabeled terminals. Though these findings are consistent with previous studies showing the nonjunctional nature of $\mathrm{D} \beta \mathrm{H}$ terminals in the amygdala (Asan, 1993, 1998) and other brain regions (Descarries et al., 1977; Seguela et al., 1990; Aoki et al., 1998), it is likely that we underestimated the degree to which $\mathrm{D} \beta \mathrm{H}$ terminals form synapses. Several factors might account for our failure to detect these synapses: the use of detergent to permeabilize membranes and improve penetration of the $\mathrm{D} \beta \mathrm{H}$ antibody, dense $\mathrm{DAB}$ reaction product that obscures the morphological features of labeled terminals, and the thin, small size of synapses that may be overlooked without serial section examination. Though we followed some non-junctional D $\beta \mathrm{H}$ terminals for 2-5 sections, this series was too small to establish whether these $\mathrm{D} \beta \mathrm{H}$ terminals ultimately formed synapses. Our results, showing that approximately $30 \%$ of $\mathrm{D} \beta \mathrm{H}$ terminals in the LA form synaptic junctions, is higher than what has been reported for the BLA (Asan, 1998) and may represent regional differences within the amygdala complex or methodological differences attributable to our use of a stronger fixative that results in better preservation of membrane ultrastructure, enabling detection of a greater number of synapses. Our study showing that $\mathrm{D} \beta \mathrm{H}$ terminals form both symmetric and asymmetric synapses, is consistent with previous studies done in basal amygdala (Asan, 1998; Li et al., 2002) and other brain regions (Seguela et al., 1990; Aoki et al., 1998). Though Li et al. (2001) reported that the proportion of symmetric and asymmetric synapses was almost equivalent in the BLA, our results showing that $\mathrm{D} \beta \mathrm{H}$ terminals form approximately twice as many symmetric synapses than asymmetric synapses, are similar to what Asan (1998) found in BLA. Though asymmetric junctions have been correlated with glutamatergic transmission and symmetric synapses with GABAergic transmission (Peters et al., 1991), the distinction in catecholaminergic systems is less clear and may instead reflect the target dendrite and the synaptic machinery present on that target. For example, though $\mathrm{D} \beta \mathrm{H}$ terminals were more likely to form symmetric rather than asymmetric synapses 
in LA, most asymmetric synapses were formed on dendritic spines, which receive most of the glutamatergic synapses in the LA (Farb et al., 1992). Though serial section analysis shows that just $7 \%$ of dendritic spines in LA receive more than one synapse, and only $2 \%$ of LA spines receive both an asymmetric and a symmetric synapse (Ostroff et al., 2010), we found that when D $\beta \mathrm{H}$ terminals synapse on spines, approximately $25 \%$ of these spines also receive synapses from other unlabeled terminals and most of these junctions are asymmetric. This observation and the prevalence of $\beta$ AR labeling at the PSDs of asymmetric synapses in dendritic spines suggest that NE may modulate glutamatergic transmission at LA spines. These results are consistent with electrophysiological findings showing that NE modulates glutamatergic neurotransmission in amygdala (Huang et al., 1996, 1998a,b) and activation of $\beta$ ARs enhances synaptic transmission in amygdala (Gean et al., 1992; Huang et al., 1998a,b), hippocampus (Raman et al., 1996), and prefrontal cortex (Ji et al., 2008). Preliminary data from our lab indicate that LA dendritic spines and shafts that are immunoreactive for $\beta A R s$ receive synaptic contacts from axon terminals originating either from the acoustic thalamus or cortex (unpublished observations), pathways known to be glutamatergic (Farb et al., 1992; Farb and LeDoux, 1997, 1999). Thus, NE may modulate synaptic transmission of these sensory pathways to the LA either by its convergence onto the same dendritic shafts and spines as cortical or thalamic axons or via activation of $\beta$ ARs on these dendritic processes.

\section{BARs ARE PRESENT IN BOTH EXCITATORY AND INHIBITORY CELLS IN THE LA}

Our confocal and EM findings, showing that the neuronal form of the $\beta A R$ is localized to both excitatory and inhibitory LA cells, are consistent with anatomical and pharmacological studies showing that $\beta$ ARs are present on pyramidal and GABAergic cells in hippocampus (Milner et al., 2000; Hillman et al., 2005; Cox et al., 2008). Within amygdala, in vitro electrophysiological studies have shown that the activation of $\beta$ ARs on pyramidal cells results in enhancement of excitatory transmission by NE whereas blockade of $\beta A R s$ by propranolol reduces excitatory transmission (Gean et al., 1992; Huang et al., 1993, 1996; Ferry et al., 1997; Buffalari and Grace, 2007) and blocks late LTP (Johnson et al., 2006) on these cells. While anatomical and in vitro studies within the amygdala have shown a relationship between NE and GABA, they have yet to demonstrate whether this association is attributable to the activation of $\beta A R s$ on GABA cells in the LA. For example, GABAergic cells in BLA receive synaptic contacts from $\mathrm{D} \beta \mathrm{H}$ terminals ( $\mathrm{Li}$ et al., 2002), indicating that NE may directly modulate GABAergic transmission. Additionally, application of NE in LA slices, suppresses feedforward GABAergic inhibition of projection neurons (Tully et al., 2007). In vivo, when the $\beta A R$ antagonist propranolol is administered i.p., the memory-enhancing effects of the $\mathrm{GABA}_{\mathrm{A}}$ antagonist

\section{REFERENCES}

Abraham, P.A., Xing, G., Zhang, L., Yu, E.Z., Post, R., Gamble,E.H., and Li,H. (2008). Betal-andbeta2-adrenoceptorinduced synaptic facilitation in rat basolateral amygdala. Brain Res. 1209, 65-73.

Agnati, L. F., Zoli, M., Stromberg, I., and Fuxe, K. (1995). Intercellular com- munication in the brain: wiring versus volume transmission. Neuroscience 69, 711-726.

Amorapanth, P., LeDoux, J. E., and Nader, K. (2000). Different lateral amygdala outputs mediate reactions and actions elicited by a fear-arousing stimulus. Nat. Neurosci. 3, 74-79.

bicuculline are blocked, while clenbuterol, the $\beta A R$ agonist, blocks the memory-impairing effects of the $\mathrm{GABA}_{\mathrm{A}}$ agonist muscimol (Introini-Collison et al., 1994). Our data showing that $\beta$ ARs are present on GABA cells in the LA provides a framework for understanding these physiological and behavioral findings.

\section{BARs AT NON-SYNAPTIC SITES}

The large proportion of non-junctional appositions formed by $\mathrm{D} \beta \mathrm{H}$ terminals in amygdala may reflect NE release via volume transmission (Descarries et al., 1977; Agnati et al., 1995) or nonsynaptic mechanisms. Consistent with these ideas are dual-label ultrastructural studies in cortex and hippocampus showing that dendrites that are immunoreactive for $\beta \mathrm{AR}$ were near catecholaminergic axons but rarely in direct contact with them, though astrocytic processes were (Aoki et al., 1989; Aoki, 1992; Aoki and Pickel, 1992; Milner et al., 2000). Our findings, showing extensive BAR immunoreactivity of glial processes, support the idea that NE might act indirectly through astrocytic processes and are consistent with previous ultrastructural studies (Aoki et al., 1994, Aoki 1992, 1997; Milner et al., 2000) and in vivo and in vitro binding studies from various brain areas showing $\beta$ ARs expression or binding in astrocytes (Burgess and McCarthy, 1985; Lerea and McCarthy, 1990; Stone and John, 1991). Activation of astrocytic $\beta$ ARs may modulate glutamatergic transmission at excitatory synapses via close appositions or glial ensheathment of these synapses (Shao and McCarthy, 1994). Additionally, astrocytic $\beta$ ARs may modulate gap junction permeability, release glucose for energy metabolism, or play a role in cytoskeletal rearrangements that accompany neuronal plasticity (for reviews, see Gibbs et al., 2008; Giaume et al., 2010).

\section{CONCLUSIONS}

Together, results from this study suggest that norepinephrine-containing terminals in the LA may engage in non-synaptic transmission in the LA. The presence of $\beta_{2}$ ARs in both excitatory and inhibitory neurons suggests that NE has a prolific role in the modulation of synaptic transmission in LA. Further, the prevalence of $\beta A R s$ in glial cells adds a further dimension to the role of $\mathrm{NE}$ in modulating synaptic transmission in LA since glial cells may play a role in regulating excitatory transmission. These data provide an anatomical foundation for interpretation of physiological and behavioral studies of the role of NE in the amygdala.

\section{ACKNOWLEDGMENTS}

The authors would like to thank Drs. Caterine D. Strader and Chiye Aoki for their generous gifts of $\beta \mathrm{AR}$ antisera and Drs. Aoki and Robert Sears for discussions about the manuscript. This research was supported by the National Institutes of Health Grants R01 MH046516 and P50 MH058911 to Joseph E. LeDoux.

Aoki, C. (1992). Beta-adrenergic receptors: astrocytic localization in the adult visual cortex and their relation to catecholamine axon terminals as revealed by electron microscopic immunocytochemistry. J. Neurosci. 12, 781-792.

Aoki, C. (1997). Differential timing for the appearance of neuronal and astrocytic beta-adrenergic receptors in the developing rat visual cortex as revealed by light and electron-microscopic immunocytochemistry. Vis. Neurosci. 14, 1129-1142.

Aoki, C., Lubin, M., and Fenstemaker, S. (1994). Columnar activity regulates astrocytic beta-adrenergic receptor- 
like immunoreactivity in V1 of adult monkeys. Vis. Neurosci. 11, 179-187.

Aoki, C., and Pickel, V. M. (1992). C-terminal tail of beta-adrenergic receptors: immunocytochemical localization within astrocytes and their relation to catecholaminergic neurons in N. tractus solitarii and area postrema. Brain Res. 571, 35-49.

Aoki,C., Venkatesan, C., Go, C.G., Forman, R., and Kurose, H. (1998). Cellular and subcellular sites for noradrenergic action in the monkey dorsolateral prefrontal cortex as revealed by the immunocytochemical localization of noradrenergic receptors and axons. Cereb. Cortex 8, 269-277.

Aoki, C., Zemcik, B. A., Strader, C. D., and Pickel, V.M. (1989). Cytoplasmicloop of beta-adrenergic receptors: synaptic and intracellular localization and relation to catecholaminergic neurons in the nuclei of the solitary tracts. Brain Res. 493, 331-347.

Asan, E. (1993). Comparative single and double immunolabelling with antisera against catecholamine biosynthetic enzymes: criteria for the identification of dopaminergic, noradrenergic and adrenergic structures in selected rat brain areas. Histochemistry 99, $427-442$.

Asan, E. (1998). The catecholaminergic innervation of the rat amygdala. $A d v$. Anat. Embryol. Cell Biol. 142, 1-118.

Asanuma, M., Ogawa, N., Mizukawa, K., Haba, K., Hirata, H., and Mori, A. (1991). Distribution of the beta-2 adrenergic receptor messenger RNA in the rat brain by in situ hybridization histochemistry: effects of chronic reserpine treatment. Neurochem. Res. $16,1253-1256$.

Aston-Jones, G., and Bloom, F. E. (1981). Norepinephrine-containing locus coeruleus neurons in behaving rats exhibit pronounced responses to non-noxious environmental stimuli. J. Neurosci. 1, 887-900.

Aston-Jones, G., Rajkowski, J., and Cohen, J. (1999). Role of locus coeruleus in attention and behavioral flexibility. Biol. Psychiatry 46, 1309-1320.

Aston-Jones, G., Rajkowski, J., and Cohen, J. (2000). Locus coeruleus and regulation of behavioral flexibility and attention. Prog. Brain Res. $126,165-182$.

Bailey, C. H., Giustetto, M., Huang, Y. Y., Hawkins, R. D., and Kandel, E. R. (2000). Is heterosynaptic modulation essential for stabilizing Hebbian plasticity and memory? Nat. Rev. Neurosci. 1, 11-20.

Balcita-Pedicino, J. J., and Rinaman, L. (2007). Noradrenergic axon terminals contact gastric preautonomic neurons in the paraventricular nucleus of the hypothalamus in rats.J. Comp. Neurol. 501, 608-618.

Buffalari, D. M., and Grace, A. A. (2007). Noradrenergic modulation of basolateral amygdala neuronal activity: opposing influences of alpha-2 and beta receptor activation. J. Neurosci. 27, 12358-12366.

Burgess, S. K., and McCarthy, K. D. (1985). Autoradiographic quantitation of beta-adrenergic receptors on neural cells in primary cultures. I. Pharmacological studies of [125I] pindolol binding of individual astroglial cells. Brain Res. 335, 1-9.

Bush, D. E., Caparosa, E. M., Gekker, A., and LeDoux, J. (2010). Beta-adrenergic receptors in the lateral nucleus of the amygdala contribute to the acquisition but not the consolidation of auditory fear conditioning. Front. Behav. Neurosci. 4:154. doi: 10.3389/ fnbeh.2010.00154.

Cox, D. J., Racca, C., and LeBeau, F. E. (2008). Beta-adrenergic receptors are differentially expressed in distinct interneuron subtypes in the rat hippocampus. J. Comp. Neurol. 509, 551-565.

Debiec, J., and LeDoux, J. E. (2004). Disruption of reconsolidation but not consolidation of auditory fear conditioning by noradrenergic blockade in the amygdala. Neuroscience 129, 267-272.

Descarries, L., Watkins, K.C., and Lapierre, Y. (1977). Noradrenergic axon terminals in the cerebral cortex of rat. III. Topometric ultrastructural analysis. Brain Res. 133, 197-222.

Dixon, R. A., Kobilka, B. K., Strader, D. J., Benovic, J. L., Dohlman, H. G., Frielle, T., Bolanowski, M. A., Bennett, C. D., Rands, E., Diehl, R. E., Mumford, R. A., Slater, E. E., Sigal, I. S., Caron, M. G., Lefkowitz, R. J., and Strader, C. D. (1986). Cloning of the gene and cDNA for mammalian beta-adrenergic receptor and homology with rhodopsin. Nature 321, 75-79.

Fallon, J. H., and Ciofi, P. (1992). "Distribution of monoamines within the amygdala," in The Amygdala: Neurobiological Aspects of Emotion, Memory, and Mental Dysfunction, ed. J. P. Aggleton (New York: Wiley-Liss, Inc.), 97-114.

Fallon, J. H., Koziell, D. A., and Moore, R. Y. (1978). Catecholamine innervation of the basal forebrain. J. Comp. Neurol. 180, 509-532.

Farb, C., Aoki, C., Milner, T., Kaneko, T., and LeDoux, J. (1992). Glutamate immunoreactive terminals in the lateral amygdaloid nucleus: A possible substrate for emotional memory. Brain Res. 593, 145-158.
Farb, C. R., Aoki, C., and LeDoux, J. E. (1995). Differential localization of NMDA and AMPA receptor subunits in the lateral and basal nuclei of the amygdala: a light and electron microscopic study. J. Comp. Neurol. 362, 86-108.

Farb, C. R., and LeDoux, J. E. (1997). NMDA and AMPA receptors are post-synaptic to auditory thalamic afferents. Synapse 27, 106-121.

Farb, C. R., and LeDoux, J. E. (1999). Afferents from rat temporal cortex synapse on lateral amygdala neurons that express NMDA and AMPA receptors. Synapse 33, 218-229.

Ferry, B., Magistretti, P. J., and Pralong, E. (1997). Noradrenaline modulates glutamate-mediated neurotransmission in the rat basolateral amygdala in vitro. Eur. J. Neurosci. 9, 1356-1364.

Gean, P. W., Huang, C. C., Lin, J. H., and Tsai, J. J. (1992). Sustained enhancement of NMDA receptor-mediated synaptic potential by isoproterenol in rat amygdalar slices. Brain Res. 594 331-334.

Giaume, C., Koulakoff, A., Roux, L., Holcman, D., and Rouach, N. (2010). Astroglial networks: a step further in neuroglial and gliovascular interactions. Nat. Rev. Neurosci. 11, 87-99.

Gibbs, M. E., Hutchinson, D., and Hertz, L. (2008). Astrocytic involvement in learning and memory consolidation. Neurosci. Biobehav. Rev. 32, 927-944.

Gray, J.A. (1978). The neuropsychology of anxiety. Br. J. Psychol. 69, 417-434.

Grillon, C., Cordova, J., Morgan, C. A., Charney, D. S., and Davis, M. (2004). Effects of the beta-blocker propranolol on cued and contextual fear conditioning in humans. Psychopharmacol. (Berl). 175, 342-352.

Hillman, K. L., Doze, V.A., and Porter,J.E. (2005). Functional characterization of the beta-adrenergic receptor subtypes expressed by CA1 pyramidal cells in the rat hippocampus. J. Pharmacol. Exp. Ther. 314, 561-567.

Howorth, P.W., Teschemacher, A. G., and Pickering, A. E. (2009). Retrograde adenoviral vector targeting of nociresponsive pontospinal noradrenergic neurons in the rat in vivo. J. Comp. Neurol. 512, 141-157.

Huang, C. C., Tsai, J. J., and Gean, P. W. (1993). Enhancement of NMDA receptor-mediated synaptic potential by isoproterenol is blocked by Rp-adenosine $3^{\prime}, 5^{\prime}$-cyclic monophosphothioate. Neurosci. Lett. 161, 207-210.

Huang, C. C., Lin, C. H., and Gean, P. W. (1998a). Potentiation of N-methyl-Daspartate currents by isoproterenol in the acutely dissociated rat amygdalar neurons. Neurosci. Lett. 253, 9-12.
Huang, C. C., Wang, S. J., and Gean, P. W. (1998b). Selective enhancement of P-type calcium currents by isoproterenol in the rat amygdala. J. Neurosci. 18, 2276-2282.

Huang, Y. Y., Nguyen, P. V., Abel, T., and Kandel, E. R. (1996). Long-lasting forms of synaptic potentiation in the mammalian hippocampus. Learn Mem. 3, 74-85.

Introini-Collison, I. B., Castellano, C., and McGaugh, J. L. (1994). Interaction of GABAergic and beta-noradrenergic drugs in the regulation of memory storage. Behav. Neural. Biol. 61 150-155.

Ji, X. H., Cao, X. H., Zhang, C. L., Feng, Z. J., Zhang, X. H., Ma, L., and Li, B. M. (2008). Pre- and postsynaptic betaadrenergic activation enhances excitatory synaptic transmission in layer $\mathrm{V} /$ VI pyramidal neurons of the medial prefrontal cortex of rats. Cereb. Cortex $18,1506-1520$.

Johnson, E. W., Wolfe, B. B., and Molinoff, P. B. (1989). Regulation of subtypes of beta-adrenergic receptors in rat brain following treatment with 6-hydroxydopamine. J. Neurosci. 9, 2297-2305.

Johnson, L. R., Hou, M., and LeDoux, J.E. (2006). Afferent specific regulation of cortical and subcortical synaptic input to the lateral amygdala by norepinephrine. Soc. Neurosci. Abstr. http:// www.abstractsonline.com/viewer/ viewAbstractPrintFriendly. asp? $\mathrm{CKey}=\{$ DBCB6EA2-C62 $1-$ 40 D 2 - A 011 C - 39 $\mathrm{C} 202 \mathrm{~A} 63 \mathrm{D} 35\} \& \mathrm{SKey}=\{13 \mathrm{~EB} 1 \mathrm{~A} 80-$ 8 F B $6-4$ C 5 B -913 C - 74 A 28 A $162 \mathrm{ECB}\} \& \mathrm{M} \mathrm{Key}=$ $\{$ D 1974 E $76-28$ A F - 4 C 1 C 8AE $8-4$ F 73B56247A7\} \&AKey= \{3A7DC0B9-D787-44AA-BD08FA7BB2FE9004\}

Lang, P. J., and Davis, M. (2006).Emotion, motivation, and the brain: reflex foundations in animal and human research Prog. Brain Res. 156, 3-29.

LeDoux, J. (2007). The amygdala. Curr. Biol. 17, R868-R874.

LeDoux, J. E. (2000). Emotion circuits in the brain. Annu. Rev. Neurosci. 23, 155-184.

Lee, H. J., Berger, S. Y., Stiedl, O., Spiess, J., and Kim, J. J. (2001). Post-training injections of catecholaminergic drugs do not modulate fear conditioning in rats and mice. Neurosci. Lett. 303, 123-126.

Lerea, L. S., and McCarthy, K. D. (1990). Neuron-associated astroglial cells express beta- and alpha 1-adrenergic receptors in vitro. Brain Res. 521, $7-14$.

Li, R., Nishijo, H., Ono, T., Ohtani, Y., and Ohtani, O. (2002). Synapses on 
GABAergic neurons in the basolateral nucleus of the rat amygdala: doublelabeling immunoelectron microscopy. Synapse 43, 42-50.

Li, R., Nishijo, H., Wang, Q., Uwano, T., Tamura, R., Ohtani, O., and Ono, T. (2001).Light and electron microscopic study of cholinergic and noradrenergic elements in the basolateral nucleus of the rat amygdala: evidence for interactions between the two systems. J. Comp. Neurol. 439, 411-425.

Maren, S. (2005). Synaptic mechanisms of associative memory in the amygdala. Neuron 47, 783-786.

McDonald,A. J., Muller,J.F., and Mascagni, F. (2002). GABAergic innervation of alpha type II calcium/calmodulindependent protein kinase immunoreactive pyramidal neurons in the rat basolateral amygdala. J. Comp. Neurol. 446, 199-218.

McGaugh, J. L. (2002). Memory consolidation and the amygdala: a systems perspective. Trends Neurosci. 25, 456.

Milner, T. A., Shah, P., and Pierce, J. P. (2000). Beta-adrenergic receptors primarily are located on the dendrites of granule cells and interneurons but also are found on astrocytes and a few presynaptic profiles in the rat dentate gyrus. Synapse 36, 178-193.

Minneman, K.P.,Wolfe,B.B., and Molinoff, P. B. (1982). Selective changes in the density of beta 1-adrenergic receptors in rat striatum following chronic drug treatment and adrenalectomy. Brain Res. 252, 309-314.

Moore, R. Y., and Card, J. P. (1984). "Noradrenaline-containing neuron systems," in Handbook of Chemical Neuroanatomy: Classical Transmitters in the CNS, Part I, eds A. Bjorklund and T. Hokfelt (Amsterdam: Elsevier), 123-156.

Murchison, C. F., Zhang, X. Y., Zhang, W. P., Ouyang, M., Lee, A., and Thomas, S. A. (2004). A distinct role for nore- pinephrine in memory retrieval. Cell 117, 131-143.

Nader, K., Majidishad, P., Amorapanth, P., and LeDoux, J. E. (2001). Damage to the lateral and central, but not other, amygdaloid nuclei prevents the acquisition of auditory fear conditioning. Learn Mem. 8, 156-163.

Ostroff, L. E., Cain, C. K., Bedont, J., Monfils, M. H., and LeDoux, J. E. (2010). Fear and safety learning differentially affect synapse size and dendritic translation in the lateral amygdala. Proc. Natl. Acad. Sci. U.S.A. 107, 9418-9423.

Palacios, J. M., and Kuhar, M. J. (1980). Beta-adrenergic-receptor localization by light microscopic autoradiography. Science 208, 1378-1380.

Peters, A., Palay, S., and Webster, H. D. F. (1991). The Fine Structure of the Nervous System. New York: Oxford University Press.

Pitkänen, A., Savander, V., and LeDoux, J. E. (1997). Organization of intraamygdaloid circuitries in the rat: an emerging framework for understanding functions of the amygdala. Trends Neurosci. 20, 517-523.

Qu, L. L., Guo, N. N., and Li, B. M. (2008). Beta1- and beta2-adrenoceptors in basolateral nucleus of amygdala and their roles in consolidation of fear memory in rats. Hippocampus 18, 1131-1139.

Rainbow, T. C., Parsons, B., and Wolfe, B. B. (1984). Quantitative autoradiography of beta 1 - and beta 2-adrenergic receptors in rat brain. Proc. Natl. Acad. Sci. U.S.A. 81, 1585-1589.

Raman, I. M., Tong, G., and Jahr, C. E. (1996). Beta-adrenergic regulation of synaptic NMDA receptors by CAMPdependent protein kinase. Neuron 16, 415-421.

Redmond, D. E. J. (1979). "New and old evidence for the involvement of a brain norepinephrine system in anxi- ety," In Phenomonology and Treatment of Anxiety, eds W. G. Fann, I. Karacan, A. D. Pokorny, and R. L. Williams (New York: Spectrum), 153-202.

Ribak, C. E., and Seress, L. (1983). Five types of bakset cell in the hippocampal dentate gyrus: a combined golgi and electron microscopic study. $J$. Neurocytol. 12, 577-597.

Roder, S., and Ciriello, J. (1993). Innervation of the amygdaloid complex by catecholaminergic cell groups of the ventrolateral medulla. J. Comp. Neurol. 332, 105-122.

Rodrigues, S. M., Schafe, G. E., and LeDoux, J. E. (2004). Molecular mechanisms underlying emotional learning and memory in the lateral amygdala. Neuron 44, 75-91.

Schiltz, J. C., and Sawchenko, P. E. (2007). Specificity and generality of the involvement of catecholaminergic afferents in hypothalamic responses to immune insults. J. Comp. Neurol. 502, 455-467.

Seguela, P., Watkins, K. C., Geffard, M., and Descarries, L. (1990). Noradrenaline axon terminals in adult rat neocortex: an immunocytochemical analysis in serial thin sections. Neuroscience 35 , 249-264.

Shao, Y., and McCarthy, K. D. (1994). Plasticity of astrocytes. Glia 11, 147-155.

Stone, E. A., and John, S. M. (1991). Further evidence for a glial localization of rat cortical beta-adrenoceptors: studies of in vivo cyclic AMP responses to catecholamines. Brain Res. 549 , 78-82.

Strader, C. D., Sigal, I. S., Blake, A. D., Cheung, A. H., Register, R. B., Rands, E.,Zemcik, B.A., Candelore, M. R., and Dixon, R.A. (1987a). The carboxyl terminus of the hamster beta-adrenergic receptor expressed in mouse $\mathrm{L}$ cells is not required for receptor sequestration. Cell 49, 855-863.
Strader, C. D., Sigal, I. S., Register, R. B., Candelore, M. R., Rands, E., and Dixon, R.A. (1987b). Identification of residues required for ligand binding to the beta-adrenergic receptor. Proc. Natl. Acad. Sci. U.S.A. 84, 4384-4388. Sullivan, G. M., Coplan, J. D., Kent, J. M., and Gorman, J. M. (1999). The noradrenergic system in pathological anxiety: a focus on panic with relevance to generalized anxiety and phobias. Biol. Psychiatry 46, 1205-1218.

Tully, K., Li, Y., Tsvetkov, E., and Bolshakov, V. Y. (2007). Norepinephrine enables the induction of associative long-term potentiation at thalamo-amygdala synapses. Proc. Natl. Acad. Sci. U.S.A. 104, 14146-14150.

Zemcik, B. A., and Strader, C. D. (1988). Fluorescent localization of the betaadrenergic receptor on DDT-1 cells. Down-regulation by adrenergic agonists. Biochem. J. 251, 333-339.

Conflict of Interest Statement: The authors declare that the research was conducted in the absence of any commercial or financial relationships that could be construed as a potential conflict of interest.

Received: 27 May 2010; paper pending published: 11 June 2010; accepted: 23 August 2010; published online: 13 October 2010.

Citation: Farb CR, Chang W and LeDoux JE (2010) Ultrastructural characterization of noradrenergic axons and beta-adrenergic receptors in the lateral nucleus of the amygdala. Front. Behav. Neurosci. 4:162. doi:10.3389/fnbeh.2010.00162

Copyright $(2010$ Farb, Chang and LeDoux. This is an open-access article subject to an exclusive license agreement between the authors and the Frontiers Research Foundation, which permits unrestricted use, distribution, and reproduction in any medium, provided the original authors and source are credited. 